\title{
ADJECTIVE CLAUSES AND ADVERBIAL CLAUSES IN "THE SECRET GARDEN" BY FRANCES HODGSON BURNETT
}

\author{
Apen Sumardi ${ }^{1}$, \\ English Language Education Program, Universitas Indraprasta PGRI \\ Mashadi Said ${ }^{2}$ \\ e-mail: apenmcc@gmail.com ${ }^{1}$
}

\begin{abstract}
This research aims to analyze the adjective and adverbial clauses in "The Secret Garden" by Frances Hodgson Burnett. The method used in this research is a content analysis which is to describes the adjective clause and adverbial clause in the novel. Data are obtained, analyzed, and described based on the sentences in the novel. The relative pronoun's adjective shows the highest percentage of 130 or $86 \%$, while relative adverbs show 22 or $14 \%$. The adjective clause in relative pronouns shows the highest percentage caused by the complex sentences, mostly describing someone or things in most sentences in the novel. Meanwhile, adjective clause in time shows 154 or $63 \%$, manner 46 or 19\%, reason 35 or 14\%, condition 6 or $2 \%$, and concession $42 \%$. Adverbial clause in time shows the highest percentage caused by most sentences tell about the time in almost every page.
\end{abstract}

Keywords: adjective clause; adverbial clause; novel

\section{Introduction}

Talking language will always be an interesting topic. Language always develops from time to time in the whole world due to communication every day. Language is a tool to connect one person to another by communication and interaction. Human communication happens through the form of language. It occurs both verbally and non-verbally through writing, reading, and sign or symbol. Language divides into two parts and is spoken and written. Spoken language is a language produced by articulate sounds. Many languages have no written form, so they only use the spoken language. In this language, much of the meaning is determined by the context.

Meanwhile, written language is the representation of a spoken or gestural through a writing system. In this language, much of the meaning is provided directly by the text. Furthermore, language also has essential functions. First, the primary function is to communicate any information. This is very helpful to state the logical facts clearly. Second, language conveys the feelings or emotions, or attitudes of somebody. For example, poetry and other literary forms can show how the feeling is. The last function is language directs people to do some action. This function can be used to requests and command to play an essential role in human life.

Talking about the language, a language that is popular in the world is English. English is a universal language that spreads out all over the world. It spreads through hundreds of countries in this universe. Through its spreading, it gives an important role in human communication in international intercourse. Many people use English to communicate with each other in daily life.

Moreover, English applies to schools, colleges, universities wherein International students from different countries and backgrounds can speak freely. Even every international meeting, both formal and informal, use English for communication. English is critical nowadays. It covers many aspects of human life, such as communication, business, entertainment, and many more. It also eases human life 
to communicate and interact with people around the world who come from different countries and backgrounds. The importance of English is so close to human life. There are four reasons why English is such as important language. First, English is the language of international communication, media, and the internet. All information mainly uses English. It is also the language of science, computers, tourism, aviation, and even diplomacy. Second, English can be used around the world. Wherever people go around the world, English is the first language to communicate and understand each other. Third, English gives access to the entertainment world. All people know that movies, books, and many other entertainments are in English. Understanding English will ease people's life. Last, English gives an excellent opportunity in career. Everybody who can speak English mainly easy to get a job. It will be beneficial and valuable.

English cannot be separated from one of the aspects of English; that is grammar. Grammar is the structure and system of a language, or languages generally considered to consist of syntax and morphology. In other words, grammar is a set structure and system that should be followed by the language users (English) in order to make the language correctly used. It means that English has a rule or system that sets up the language to make sense. Then, it also makes English sounds proper and understandable.

Moreover, grammar is essential when people apply it in writing contexts such as books, articles, journals. It will make the use of English smoothly. Grammar is one of the most critical elements of English. It sets the language to be more regular and systematic. It also makes the readers write context (books, articles, etc.) easy to understand using grammar. The correct grammar will make people use English fluently and confidently. It also becomes a key to master English well. By knowing and understanding grammar, it can avoid making some errors during the use of English. Not only that, but grammar is also used to interpret literature that deals with the composition, and the composition itself need to be measured by grammar. In this case, grammar can easily help to interpret sentence structure sets correctly and makes sense. This is how important grammar to build sentence structure so that it will be more perfect. Grammar can be one of the most complex and challenging. It is caused by many rules which should be understood well so that people feel puzzled. Moreover, English has a very complex verb that constantly changes in time. Many people think that grammar is the most challenging element in learning English, among other elements.

Many people think that grammar is not essential in the English language. They consider that the appropriate English grammar is only for teachers and scholars because there is no impact on daily life. This is not true. Grammar is the foundation for communication. Without grammar, a message will be challenging to understand and hard to be accepted.

On the other hand, using grammar will be easy to accept that message's function and meaning. There are three reasons why grammar is essential. First, grammar can improve the development of fluency during the use of English. When people understand and know grammar very well, they will easily express their idea without any obstacles and difficulties. As a result, they can easily talk, read and write efficiently. Second, clear communication will be impossible without good grammar. Proper grammar will prevent misunderstanding during communication. The last, by understanding grammar, people will think more logically and clearly. People will be more careful and accurate when using English after learning the grammar. In grammar, especially in writing form, sentence building is necessary because it is essential in every writing paragraph.

Moreover, it will easily find a complex sentence in the writing form, which influences the sentence structure and connects to another sentence to make the excellent structure. Then, the sentence transforms into the clause. The clause itself has both a subject and a predicate.

In English grammar, the clause is the smallest grammatical unit that can express a complete proposition. A clause is defined as a grammatical structure containing a subject and a predicate. A clause is essentially a phrase but with both a subject and predicate. Clauses are either dependent or independent. An independent clause can exist by itself as a complete sentence, while a dependent clause cannot. This is how a vital clause in a sentence or paragraph can explain the meaning of the message conveyed using the clause in every sentence or paragraph to be easily understood. Three clauses become the main English grammar study; they are the adjective, adverbial, and noun clauses. Adjective clauses modify nouns or pronouns. An adjective clause nearly always appears immediately following the noun 
INFERENCE: Journal of English Language Teaching

Vol. 3, No. 1, April - July 2020

p-ISSN: 2615-8671

e-ISSN: 2615-868X

or pronoun. Adverbial clauses usually modify verbs, in which case they may appear anywhere in a sentence.

Meanwhile, noun clauses are not modifiers, so they are not subordinators like adjectives and adverbs, and they cannot stand alone. In this research, only two clauses will be explained; they are the adjective and adverbial clauses. Those two clauses need to be researched due to their essential use in writing form. Not only that reason but also the complex sentences where the adjective clause and adverbial clause appear should be analyzed deeply to have a good understanding of this problem.

Adjective clauses and adverbial clauses are the parts of complex sentences. Complex sentences are fascinating components of the English language. When used properly, they can add depth to the writing. Complex sentences contain an independent clause and at least one dependent clause. An independent clause can stand alone as a sentence. It always makes a complete thought. A dependent clause cannot stand alone, even though it has a subject and a verb. Adjective clauses and adverbial clauses are often used in the sentence of English. Their existence is very crucial when the sentence is describing the complex form. For instance, there is mostly at least one adjective clause or adverbial clause used in a paragraph. Those two clauses often appear to describe sentences long, even though there is only one predicate. In this research, the adjective and adverbial clauses are considered part of English clauses that often appear in English paragraphs. These clauses need to be analyzes to achieve a better understanding of how these clauses work in sentences.

According to DeCapua $(2008 ; 32)$, "Adjectives are usually characterized as descriptive or modifying words because of their functions in a sentence." Based on this definition, adjectives are characterized as descriptive means describing words to make them more detailed, make sense, and understandable. Adjective as descriptive also means serving or seeking to describe the quality of nouns about physical condition, shape, size, color, and many more. Furthermore, this will make English phrases or sentences more straightforward to understand and make sense so that the use of adjectives in English is essential. Not only as descriptive, but DeCapua also stated that adjectives also modify words because of the functions in a sentence. Indeed, the primary function of an adjective is to modify words/nouns to provide more detail. This can be from size to temperature to personality. This function makes a noun have more sense in meaning.

Koopman (2013: 87) stated, "Clause is the structure of various types of constituents in more detail, beginning with structures near the level." This definition gives an understanding that clause is the structure of various types of constituents. A constituent is a linguistic part of a more significant sentence, phrase, or clause. For instance, all the words and phrases that make up a sentence are said to be constituents of that sentence. A constituent can be a morpheme, word, phrase, or clause. In this case, Koopman said that the constituents in more detail, beginning with structures near the level.

Furthermore, every sentence (and every phrase and clause) has constituents. That is to say, and every sentence is made up of parts of other things that work together to make the sentence meaningful. Constituents in grammar define the structural pieces of a sentence, phrase, or clause. Constituents can be phrases, words, or morphemes. In short, Koopman gives a more detailed understanding of the clause itself by talking about constituents. Falk (2006: 191) said, "Adjective clause is a clause that works to describe (modify) a noun or pronoun. It always is a subordinate clause. It appears immediately after the word it describes (modifies)." This definition gives to understand that this clause is to describe a noun or pronoun. It is for providing detailed information towards the noun or pronoun it modifies. An adjective clause is also a subordinate clause. This means that this clause cannot stand alone as a complete sentence; it merely complements a sentence's main clause, thereby adding to the whole unit of meaning. Because a subordinate clause depends on the main clause to be meaningful, it is also referred to as a dependent clause. Falk also stated that the adjective clause appears immediately after the word it modifies. This means that the position of the adjective clause is after the word it modifies.

Gelderen (2010: 198) stated, "Adjective clause is finite clauses that function as modifiers." This definition gives understanding that adjective clause is finite clauses. A finite clause is the main clause or a subordinate clause with a verb to show tense. The verb can be in the present tense or past tense. The tense can be changed from the present tense to the past tense or past tense to the present tense. Because the verb in the present tense or past tense is called a finite verb, the clause containing a finite 
verb is called a finite clause. Galderen continued that finite clause has function as modifiers. This to modify nouns to give detailed information so that the sentence will be understandable. As mentioned in the adjective's theory, its function is to modify nouns or pronouns to give detailed information and make the sentence sense. This opinion is so clear that the adjective clause is easy to analyze in every sentence. Galderen also divides the adjective clause into two types, and they are relative pronoun and relative adverb.

According to DeCapua (2008: 33), "adverb is a word that describes or modifies a verb, and adjective, or another adverb." The definition gives understanding that adverb is a word to modify verb, adjective, or another adverb. When it modifies those elements, adverbs provide more information about that other descriptive word. So, it is easy to identify an adverb in a sentence. Identifying adverbs in a sentence is not too difficult. It can be done by considering its function in the sentence. If it is describing a verb, adjective, or other adverb means that it is an adverb. An excellent way to understand adverbs is to think about them as the words that provide context. Specifically, adverbs describe how, where, when, in what manner, and to what extent something is done or happens. Typically, we can spot an adverb because it often ends in -ly, but many adverbs do not end in this way. Moreover, adverbs can be used in many combinations with each other.

Based on Murcia \& Freeman (2003: 381), an "adverb is part of speech that describes an adjective, another adverb or a verb. Adverb gives more information about how an action was performed. In general, they answer questions like how, why, where, and when." This definition explains that an adverb has the primary function to describe an adjective, another adverb, or a verb that describes words as modifying words to make them more straightforward and detailed. Like what Galderen stated, adverbs provide information about the manner, place, time, frequency, certainty, or other circumstances or the activity denoted by the verb or verb phrase. This theory supports what Galderen stated. Then, in this theory, there is a sentence "In general, they answer questions like how, why, where, and when.", which means that adverbs are a comprehensive collection of words that may describe how, where, or when an action took place. They may also express the speaker's viewpoint about the action, the intensity of an adjective or another adverb, or several other functions.

According to Miller (2002: 65), "Adverbial clauses modify verbs, but they modify whole clauses. Their other key property is that they are adjuncts since they are typically optional constituents in sentences. They are traditionally classified according to their meaning." The definition clarifies that the adverbial clause's function is to modify verbs and modify whole clauses. Then, Miller also stated that adverbial clauses are adjuncts. Adjunct is an optional or structurally dispensable part of a sentence, clause, or phrase that, if removed or discarded, will not otherwise affect the remainder of the sentence. An adjunct is usually an adverb used to modify a verb. When used as an adverb, an adjunct will usually indicate a reason, a time, a concession, manner, and condition in Miller's last statement, which said that they (adverbial clauses) are traditionally classified according to the meaning and, as mentioned above, classified according to the meaning such as clause of time, the clause of place, clause of contrast, clause of cause, clause of condition, the clause of manner, clause of exception, and clause of degree. This is what adverbial clauses classified according to the meaning.

Based on Celce-Murcia \& Larsen-Freeman (1999, p. 381), the "adverb is part of speech that describes an adjective, another adverb or a verb. Adverb gives more information about how an action was performed. In general, they answer questions like how, why, where, and when." This definition explains that an adverb has the primary function to describe an adjective, another adverb, or verb. Are describing words means modifying words to make them more precise and more detailed. Like what Galderen stated, adverbs provide information about the manner, place, time, frequency, certainty, or other circumstances or the activity denoted by the verb or verb phrase. This theory supports what Galderen stated. Then, in this theory, there is a sentence "In general, they answer questions like how, why, where, and when.", which means that adverbs are a comprehensive collection of words that may describe how, where, or when an action took place. They may also express the speaker's viewpoint about the action, the intensity of an adjective or another adverb, or several other functions.

On the other hand, according to Burks \& Wishon (as cited in Kehler, 2002, p. 155) stated, "adverbial clause is a dependent clause used as an adverb; it, therefore, can modify a verb, an adjective, a verbal, another adverb, or a sentence." This definition gives understanding that basically, this is the same as the adjective clause. The difference is only between adverb and adjective. In an adverbial 
INFERENCE: Journal of English Language Teaching

Vol. 3, No. 1, April - July 2020

p-ISSN: 2615-8671

e-ISSN: 2615-868X

clause, the adverb plays a vital role in the sentence. Burks \& Wishon stated that the adverbial clause is a dependent clause used as an adverb. This means that since they are dependent, they must have subordinating conjunction to connect them to the sentence's rest. Hence, they can modify a verb, an adjective, a verbal, another adverb, or a sentence. Adverbial clauses can be placed at the beginning, middle, or end of a sentence. When placed at the beginning or in the middle, they require a comma to offset them from the sentence's rest. However, when the adverb clause is at the end of a sentence, no comma is needed.

The writer analyzes the novel to find adjective clauses and adverbial clauses. The terms of the novel are various. Many experts have their theories in defining the novel. Abrams \& Harpham (2009; 226) stated, "Novel is a great variety of writings that have in common only the attribute of being extended works of fiction written in prose." This definition explains that the novel is a literary work in writing form that contains a fiction story in prose. The writings are mostly longer than short stories with some problems from the characters and a bit complicated. It also contains many characters, plots, and settings so that the story connects each other. The novel is narrative. It is known that connected narrative events, real or imaginary, are presented in the sequence of written or spoken words, sounds, still or moving images, or combinations. From this narrative, the novel can be interesting, and the story will be live to be enjoyed by the readers. The plot will be a sequence from one time to another, one place to another, one character to another, and it is like real life. The novel can be defined as an extended work of prose in fiction. This comes from the Italian novella "Little New Thing," which was a short prose piece. The novel has become an increasingly popular form of fiction since the early eighteenth century. However, prose narratives were written long before then. The term denotes a prose narrative about characters and their actions in what is recognizably everyday life. The novel is sometimes unusual. It is due to the imaginative feature. Sometimes, the novel tells a story about an impossible thing that never happens in real life. The story tells what is in out of the human mind and feels unusual. This is one reason why the novel becomes exciting and has many people like it.

\section{Method}

The writer uses descriptive qualitative research. Qualitative research is a method that seeks answers to questions and involves the collection of evidence. Qualitative research uses a wide range of techniques such as in-depth qualitative interviews, participant and non-participant observation, field notes focus groups, document analysis, and several other data collection methods. The method used in the research is a content analysis that is to find adjective clauses and adverbial clauses in "The Secret Garden" by Frances Hodgson Burnett. This research is to find the adjective clause and adverbial clause in "The Secret Garden" by Frances Hodgson Burnett. The title of this research shows the syntax and the literary work so that the research is suitable for qualitative research.

In this research, the data is from the novel "The Secret Garden" (Burnett, 1993). This novel was published in London in 1993, which consists of 27 chapters and 221 pages. The writer takes sentences which contain adjective clause and adverbial clause in the novel. The variable of adjective clauses is analyzing its types. There are two types of adjective clauses, and they are relative pronoun and relative adverb. The variable of adverbial clauses also analyzing its types. There are five types of adverbial clauses: reason, time, concession, manner, and condition.

In this research, some steps of collecting data are: 1) Identify the purposely selected document for the proposed study. In this research, the document is the text from "The Secret Garden" by Frances Hodgson Burnett. 2) Indicated the types of data to be collected. The writer reads all contents in the novel, which contains adjective clauses and adverbial clauses. Then, the writer marks the sentences and classifies whether an adjective clause or an adverbial clause. 3) Data discussion. The collected data will be classified following the objective of this research into a data card.

For analyzing data in this study, the writer does some steps: 1) Reading some books and other sources relevant to the adjective clause and adverbial clause. 2) Reading "The Secret Garden" by Frances Hodgson Burnett periodically. 3) Identifying data which contain adjective clause and adverbial clause. 4) Putting them into the table of the research instrument. 5) Analyzing and describing the sentences based on theory. 6) Interpreting the data. 7) Drawing conclusion. 8) Writing the final report.

\section{Results and Discussion}


The result of this research contains many sentences which show adjective clause and adverbial clause. From the sentences that have been collected, the researcher can present the percentage of the adjective clause in the table and diagram below:

Table 1

The percentage of adjective clause

\begin{tabular}{|c|c|c|c|}
\hline No & Types of Adjective Clause & $\begin{array}{l}\text { Times of } \\
\text { show up }\end{array}$ & $\begin{array}{l}\text { Percentage in } \\
\text { percent }(\%)\end{array}$ \\
\hline 1. & Relative pronoun & 130 & $\mathbf{8 6 \%}$ \\
\hline 2. & Relative adverb & 22 & $14 \%$ \\
\hline
\end{tabular}

Table 2

The percentage of adverbial clause

\begin{tabular}{|c|c|c|c|}
\hline No & Types of adverbial clause & $\begin{array}{l}\text { Times of } \\
\text { show up }\end{array}$ & $\begin{array}{c}\text { Percentage in } \\
\text { percent }(\%)\end{array}$ \\
\hline 1. & Time & 154 & $\mathbf{6 3 \%}$ \\
\hline 2. & Manner & $\mathbf{4 6}$ & $\mathbf{1 9 \%}$ \\
\hline $\mathbf{3 .}$ & Reason & $\mathbf{3 5}$ & $\mathbf{2 5}$ \\
\hline 5. & Condition & $\mathbf{6}$ & $\mathbf{2 \%}$ \\
\hline
\end{tabular}

\section{Adjective Clause in "The Secret Garden" by Frances Hodgson Burnett}

After analyzing the data found in "The Secret Garden" by Frances Hodgson Burnett, the writer can conclude that adjective clauses that emerge in "The Secret Garden" are: relative pronoun is $86 \%$, and relative adverb is $14 \%$.

The two types of adjective clause according to Galderen, relative pronoun shows the higher percentage that is $86 \%$ than relative adverb $14 \%$. It shows how relative pronoun appears more than relative adverb so that the existence in the novel is significant.

The relative pronoun is shown $86 \%$ in the novel. Relative pronouns show the highest percentage because the author uses complex sentences that mostly describe someone or things. The adjective clause in relative pronoun appears on almost every page. The author often uses the adjective clause when he describes the main characters or other characters. The author's sentence also tends to describe things like a tree, house, and other things containing the adjective clause in relative pronoun.

Meanwhile, the relative adverb appears $14 \%$ in the novel. Relative adverb shows a lower percentage than the relative pronoun. Relative adverb arises in the novel is only a few. It is caused by most of the sentences containing the adjective clause do not describe the time, or the place, as well as the relative adverb, should describe. It makes the existence of relative adverb only quite a few rather than the relative pronoun.

\section{Adverbial Clause in "The Secret Garden" by Frances Hodgson Burnett}

After analyzing the data found in "The Secret Garden" by Frances Hodgson Burnett, the writer can conclude that the adverbial clauses which emerge in "The Secret Garden" are $63 \%$, manner is $19 \%$, the reason is $14 \%$, the condition is $2 \%$, and concession is $2 \%$. According to Miller, after various adverbial clauses, time shows the highest percentage among other adverbial clauses that is $63 \%$. Time appears very often, and it becomes the highest percentage.

Adverbial clause in time shows the highest percentage, about $63 \%$. It is caused by the author mostly talked about the time on almost every page. An adverbial clause in time arises in the paragraph describing the story's situation regarding the plot of each character in the novel. The author often uses 


\section{INFERENCE: Journal of English Language Teaching}

Vol. 3, No. 1, April - July 2020

p-ISSN: 2615-8671

e-ISSN: 2615-868X

the word 'when' to describe the adverbial clause's situation in time. This is why the adverbial clause in time arises the highest.

The second is the adverbial clause in manner. It appears about $19 \%$ in the novel. The adverbial clause in a manner mostly appears when the author tells the characters while doing something. The author tells the manner many times when the characters do something. The word 'as if' arises in every sentence that belongs to the adverbial clause in manner.

The third is the adverbial clause in reason with 14\%. This appears when the author tells the story about the characters that contain how they do something. The word "because' arises the most in the novel, and it becomes one of a word that belongs to the adverbial clause in reason.

The fourth is the adverbial clause in concession. It contributes $2 \%$ to the whole adverbial clause. This appears only $2 \%$ because the author only tells a few sentences which contain the contrary. It can be counted the contrary sentences in the novel. That is why the adverbial clause in concession only $2 \%$.

The lowest is the adverbial clause in condition with less than $2 \%$. The author seldom uses conditional sentences in the novel. Fingers can count the use of conditional sentences in the novel. So, there are only two sentences that belong to the adverbial clause in condition.

\section{Conclusions}

After the analysis had been done, the researcher concludes that in the novel entitled "The Secret Garden" by Frances Hodgson Burnett, it can be indeed concluded that there are 152 data in the kinds of the adjective clause and 245 data in the kinds of the adverbial clause. The analysis has two objectives. The first objective is to analyze the adjective clause, and the second is to analyze the adverbial clause in the novel.

In "The Secret Garden" by Frances Hodgson Burnett, the adjective clause shows that the relative pronoun is more dominant than the relative adverb. The relative pronoun is $86 \%$, and the relative adverb is $14 \%$. It shows how the relative pronoun appears more than the relative adverb. It appears far enough from the relative adverb, which the author almost uses the relative pronoun in every sentence contain the adjective clause. The adverbial clause in relative pronoun becomes the highest percentage because the author uses complex sentences that mostly describe someone or things. Meanwhile, the adverbial clause in relative adverb shows the lowest percentage because it arises in the novel quite a few. It is caused by most sentences containing adjective clause do not describe the time or place, as well as the relative adverb, should describe.

The adverbial clause in "The Secret Garden" by Frances Hodgson Burnett shows that; the reason is $14 \%$, time is $63 \%$, the concession is $2 \%$, manner is $19 \%$, and the condition is $2 \%$. Time is the highest percentage of all kinds of adverbial clauses that arise in the novel. It shows the time is dominant among others. It appears on almost every page in the novel that the author writes them a lot. Adverbial clause in time shows the highest percentage caused by the author mostly tell about the time in almost every page. The adverbial clause in manner appears $19 \%$ caused by the author tells the characters while doing something. The adverbial clause in reason appears $14 \%$ caused by the author telling the story about the characters, which contains the reason they do something. In concession, the adverbial clause contributes $2 \%$ because the author only tells a few sentences that contain the contrary. An adverbial clause in condition becomes the lowest percentage with $2 \%$ because the author seldom uses the novel's conditional sentence.

\section{References}

Abrams, M.H \& Harpham, G. G. (2009). A Glossary of Literary Terms. Boston: Boston: Wordsworth Cengage Learning.

Burnett, F. H. (1993). The secret garden. Macmillan Education UK.

Celce-Murcia, M., \& Larsen-Freeman, D. (1999). The Grammar Book: An ESL/EFL Teacher's Course (2nd ed.). Heinle \& Heinle Publishers.

DeCapua, Andrea. (2008). Grammar for Teachers. New York: College of New Rochelle.

Falk, Y. N. (2006). Subject and Universal Grammar. Cambridge: Cambridge University Press.

Gelderen, E. v. (2010). An Introduction to the English Grammar. Amsterdam: John Benjamin Publishing. 
INFERENCE: Journal of English Language Teaching

Vol. 3, No. 1, April - July 2020

p-ISSN: 2615-8671

e-ISSN: 2615-868X

Kehler, A. (2002). Coherence, reference, and the theory of grammar. CSLI Publications.

Koopman, H. (2013). An Introduction to Syntactic Analysis and Theory. New Jersey: WileyBlackwell.

Miller, J. (2002). An Introduction to English Syntax. Edinburg: Edinburg University Press.

Muller, S. (2016). Grammatical Theory: From Transformational grammar to constraint-based approaches. Berlin: Language Science Press. 